\title{
Monsoon Impact on the Air Quality During SAR-CoV-2 Pandemic Spread in Central Peninsular Malaysia and Sabah: Pre, During and Post Lockdown Scenarios
}

\author{
M.V. Prasanna ${ }^{1 *}$ and S. Chidambaram ${ }^{2}$ \\ ${ }^{1}$ Department of Applied Geology, Faculty of Engineering and Science, Curtin University, Malaysia \\ CDT 250, 98009 Miri, Sarawak, Malaysia \\ ${ }^{2}$ Water Research Centre, Kuwait Institute for Scientific Research, P.O. Box 24885, 13109 Safat, Kuwait \\ $\triangle$ prasanna@curtin.edu.my
}

Received February 21, 2021; revised and accepted August 11, 2021

\begin{abstract}
Malaysia is considered as one of the countries with the highest novel corona virus (COVID-19) infected cases in Southeast Asia. Recent studies have identified that the air quality of a region also governs the transmission of the virus through pollutants. Hence, a study was conducted to assess the influence of air quality on the COVID-19 pandemic spread in central Peninsular Malaysia and Sabah. An attempt was also made to infer the effect of monsoonal precipitation on air quality. Central Peninsular Malaysia consists of major cities like Kuala Lumpur, Selangor and Putrajaya. These cities are highly populated, with the expansion of industrial activities, rapid urbanisation and greater usage of vehicles has resulted in air quality deterioration. Such conditions have led to related public health issues, compared to Sabah in east Malaysia. In this study, COVID-19 infected cases, air quality index (AQI) and precipitation data were collected from 25 January to August 2020 to infer the relationship of air quality to the pandemic spread before, during and after the implementation of lockdown periods in the country, referred as movement control order (MCO). The lockdown periods fall under various monsoon climate patterns in the country. Interpretation of data reveals that the variation in air quality correlates with the infected cases. Improved air quality was observed during the last phase of MCO with a lesser number of infected cases. The HYSPLIT model was adopted to study the backward air mass trajectories for different time frames to identify the variation in the sources of pollutants reaching the study area. The study determined that the air pollutants have reached the study area from various directions, reflecting a mixed contribution from the ocean and land area. The relationship between high precipitation (during inter-monsoon and SW monsoon) and improved air quality reveals the washout effect of air pollutants. The outcome of this study inferred that the variation of air quality and precipitation rates facilitate the pandemic spread in this region in addition to the other meteorological factors, apart from individual immune capacity and social distancing.
\end{abstract}

Keywords: COVID-19; Air pollutants; Inter-monsoon; Washout effect; MCO.

\section{Introduction}

Since December 2019, the COVID-19 spread has resulted in a significant acute respiratory disease, with a high possibility of human-to-human transmission (Wu et al., 2020). Common signs of this pandemic are respiratory illness, cough and fever. The relationship between COVID-19 and different conditions of the atmosphere and the biosphere were studied and understood by researchers. The studies reported that the spread of infectious diseases may also be influenced by meteorological variables such as temperature, humidity, 
air quality and wind speed (Chen et al., 2020; Ma et al., 2020; Poole, 2020; Sajadi et al., 2020; Wang et al., 2020). Air quality parameters such as $\mathrm{NO}_{2}, \mathrm{SO}_{2}, \mathrm{PM}_{10}$ and $\mathrm{PM}_{2.5}$ were observed in the COVID-19 period and the pollution levels were found to be decreased during the lockdown, due to the closure of industries and restricted usage of vehicles in major cities of the world (Otmani et al., 2020; Wang et al., 2020a; Muhammad et al., 2020; Chauhan and Singh, 2020).

The environmental and health status of a given population are adversely affected by the air pollution. The high release of pollutants like smoke and other forms of waste into the air had a significant impact since they were emitted faster than the atmosphere could absorb and disperse (Enger and Smith, 2000). In the second half of the twentieth century, rapid progress in the level of industrial activities and urbanisation posed a serious threat to the air quality (Ramanathan and Feng, 2009).

The number of industries continues to increase in Malaysia and hence there is a dependent population increase in both urban and industrial regions (DOS, 2012). Forest fires, industrial pollution and motor vehicles in the country cause changes in the atmosphere, contributing to climate change (Aghamohammadi and Isahak, 2018; Brohi et al., 2018). Air pollution in Malaysia has a negative impact on various ecosystems including forest, agriculture and human health (Afroz et al., 2003; Ishii et al., 2004). The air pollution index (API) shows that the urbanisation process led to a decrease in air quality (Ling et al., 2010), along with the changes in meteorological variables (Chng et al., 2010). Air pollutants affect the immune response of the lungs and results in inflammatory reactions, which can increase the risk of respiratory infections (Lambert et al., 2003).

Malaysia is a developing country in Southeast Asia, reported with a significant number of infected COVID-19 cases, 78,499 as of 11 December 2020. There are very few studies on COVID-19 in the country, which mainly focuses on the general behaviour of people to COVID-19 (See et al., 2020; Azlan et al., 2020; Che Mat et al., 2020; Abdullah et al., 2020). There is a research gap on meteorological influence, particularly air quality to COVID-19 spread in the country. In order to fill the above research gap, this study was formulated to examine the effect of air quality on the transmissivity of the virus during, pre-lockdown, lockdown and post-lockdown periods in the country. The monsoonal precipitation influence on the air quality was also tested. Finally, this study determines the sources of air pollutants reaching the study area using backward air mass trajectories at different time frames.

\section{Materials and Methods}

\section{Study Location and Climate}

Malaysia is located between $4.2105^{\circ} \mathrm{N}$ and $101.9758^{\circ}$ with an area spread of $329,960.22 \mathrm{~km}^{2}$. Malaysia consists of two large landmasses, Peninsular Malaysia (West Malaysia) and East Malaysia in northern Borneo territories (Ismail et al., 2017). Peninsular Malaysia covers a major part of the Malay Peninsula (14 states) and East Malaysia has two large states namely Sabah and Sarawak. The present study concentrates on central Peninsular Malaysia, which consists of Kuala Lumpur, Selangor and Putrajaya (Figure 1). These regions are considered to be more developed with respect to urban and industrial regions than in Sabah (Eastern Malaysia). The region experiences two monsoon seasons, southwest (May to September) and northeast (November to March). These seasons are separated by very short inter-monsoon months (April and October). Among the monsoon periods, the northeast monsoon has been known to record a higher amount of rainfall, marked as the most drenched period, when compared to the southwest monsoon (drier period). The average temperatures vary from 25 to $35^{\circ} \mathrm{C}$. Pleasant weather in west Malaysia is observed between January and February, in eastern Malaysia (Sabah) during April, and in Sarawak from June to July. The yearly average rainfall in west Malaysia is 2,500 $\mathrm{mm}$ and East Malaysia is $5,080 \mathrm{~mm}$.

\section{Data Collection}

The study encompasses the analysis of total cases, new cases and total deaths for the country from 25 January to 31 August 2020, which represents the pre-lockdown, lockdown and post-lockdown periods. The above data were collected from the Our World in Data website (https://ourworldindata.org). Air quality index (AQI) data was collected from the Air Quality Historical Data Platform website (aqicn.org/data-platform), sourced from the Malaysia Department of Environment (DOE) and Air Pollutant Index Management System. The collected data are not fully verified or validated. AQI is used for defining and classifying Malaysia's ambient air quality based on potential public health implications (DOE, 1997). It's a non-dimensional number calculated from the average daily pollutant concentration in a city (Dominick et al., 2012; DOE, 2012). AQI consists of five basic pollutants such as $\mathrm{O}_{3}, \mathrm{CO}, \mathrm{SO}_{2}, \mathrm{NO}_{2}$ and 


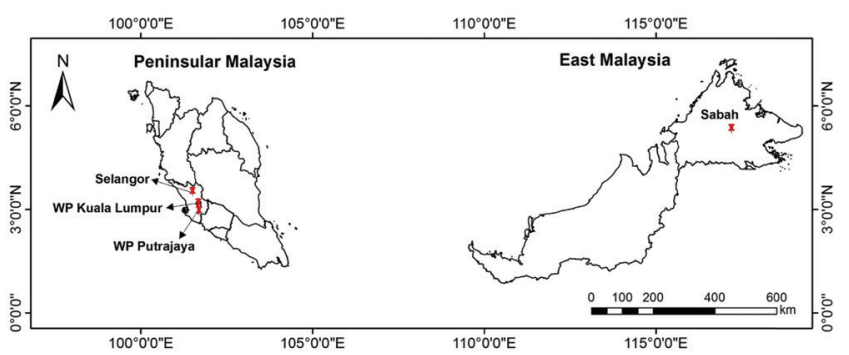

Figure 1: Air quality monitoring stations in Malaysia.

$\mathrm{PM}_{10}$. The air quality levels are classified as good (AQI 0-50), moderate (AQI 51-100) and unhealthy (101-150), defined by the US-EPA 2016 standard. Precipitation data were collected from the NASA website (https:// power.larc.nasa.gov). Hybrid Single-Particle Lagrangian Integrated Trajectory (HYSPLIT) transport model provided by the US National Atmospheric and Oceanic Administration (NOAA) Air Resources Laboratory (ARL) was used for backward air mass trajectories.

\section{Results}

\section{COVID-19 Pandemic Spread in Malaysia}

The first COVID-19 case was recorded on 25 January 2020 in the country. Since the cases started increasing significantly in early March 2020, the country has announced several lockdown periods referred to as movement control order (MCO) to increase social distancing and retard the transmission rate of the virus.
The first MCO was implemented on $18^{\text {th }}$ March 2020 and extended until 12 May 2020 in three different phases. Then the country moved into the conditional movement control order (CMCO) from 13 May 2020 to 9 June 2020 , followed by recovery movement control order (RMCO) from 10 June 2020 to 31 August 2020. So, the following discussion is based on pre-lockdown (i.e before 18 March 2020), during lockdown (18 March to 12 May 2020) and post-lock down (13 May to 31 August 2020).

Figure 2 explains the COVID-19 trends of total cases, new cases and total deaths in the country from 25 January to 31 August 2020, which covers all the periods of MCOs. During pre lockdown period few new cases were identified in February 2020, and the cases exponentially increased in early March, which has eventually lead to the implementation of the first MCO in mid-March 2020. The total number of cases was increased gradually and a sharp increase was observed prior to the implementation of MCO. There were no death cases reported during this period.

During MCO periods, the total cases increased gradually and it was higher and a significant number of death cases were also observed. The number of total cases and death cases stabilized at the end of this period, with the decreasing number of new cases in the country. This indicates the MCO periods have been effective and social distancing has reduced the pandemic spread significantly at the last phase of MCO. During the short

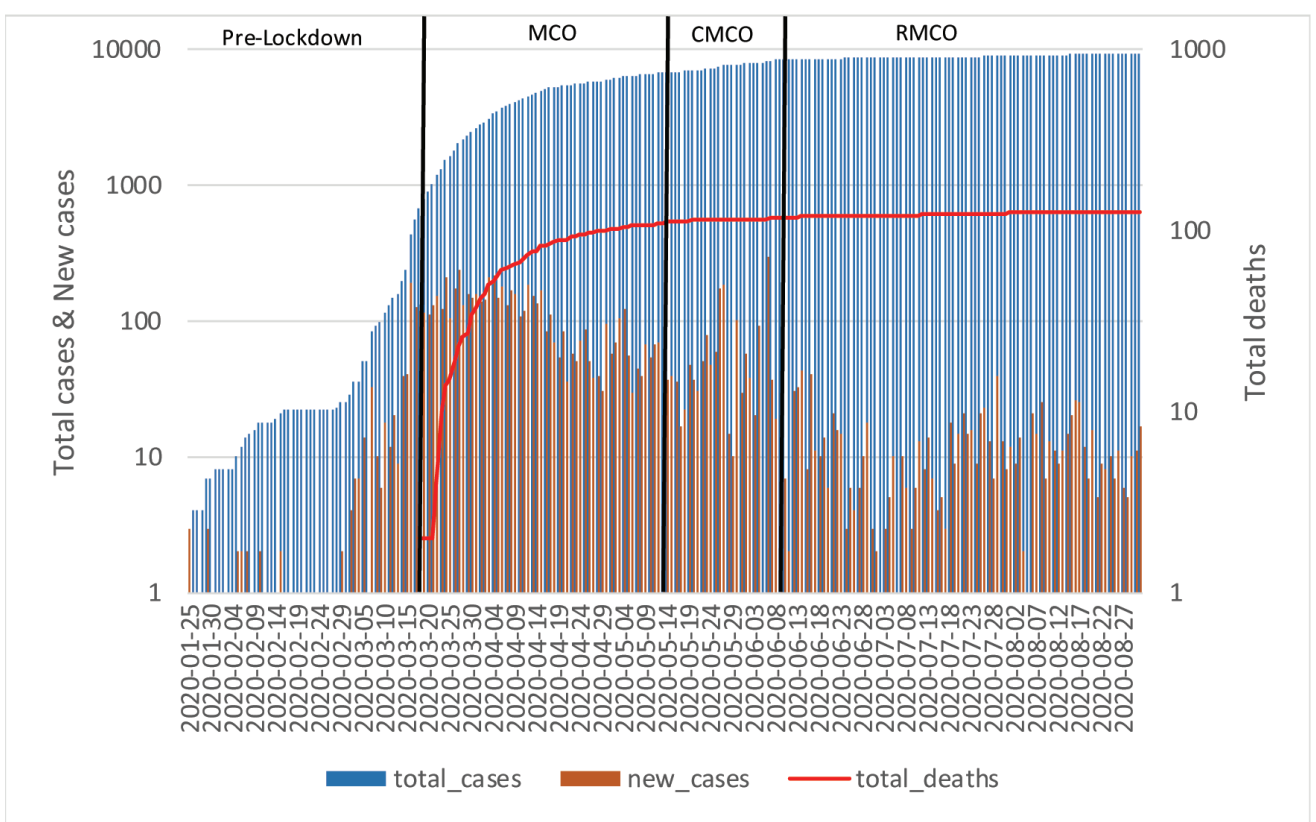

Figure 2: COVID-19 infected cases trend in Malaysia during pre lock down, lock down and post lock down periods. 
period of $\mathrm{CMCO}$, the total cases and death reports were stabilized, but there was a fluctuation in the number of new cases. This is due to the partial operational activity allowed in the country, which has relaxed the social distancing promoting the pandemic spread.

It is interesting to observe that the number of new cases significantly decreased during RMCO compared with $\mathrm{MCO}$ and $\mathrm{CMCO}$ periods. Furthermore, the number of total cases and total death reports were almost stable. This indicates the recovery stage, as the people were aware of the standard operational plans (SOP) implemented in the country to curtail the COVID-19 spread. Overall, the pandemic spread in the country was gradually decreasing from MCO to RMCO.

\section{Rainfall Pattern During the Study Period}

Precipitation data for Kuala Lumpur (representing west Malaysia) and Sabah (representing east Malaysia) were collected during the study period. The collected data from 25 January to 31 March belongs to NE monsoon; 1 to 30 April belongs to short inter-monsoon; 1 May to 31 August belongs to SW monsoon. Comparatively, a high precipitation was recorded for NE monsoon in the Kuala Lumpur region ranging from 0.05 to 27 $\mathrm{mm}$ with an average of $5 \mathrm{~mm}$. Similarly, during intermonsoon, high precipitation was recorded in Kuala Lumpur ranging from 0.12 to $38 \mathrm{~mm}$ with an average of $10 \mathrm{~mm}$. But in the SW monsoon, high precipitation was recorded in Sabah ranging from 0.03 to $90 \mathrm{~mm}$ with an average of $10 \mathrm{~mm}$.

\section{Discussion}

\section{Impact of Air Quality to COVID-19}

The air quality of a region was identified by researchers as a significant factor for the transmission of the virus (Lambert et al., 2003; Steyn and Castelli, 2010). The major cities in Peninsular Malaysia such as Kuala Lumpur, Selangor and Putrajaya, and Sabah in East Malaysia were selected for further discussion.

\section{Kuala Lumpur}

A declining trend of AQI was observed during the initial stage of pre lockdown period which subsequently increased at the end of pre-lockdown period with a concurrent increase in new cases (Figure 3). This indicates that air quality is an influencing factor for the pandemic spread. At the beginning of the MCO period, there were constant AQI values $(>50)$ reflecting moderate air quality (Mabahwi et al., 2015; Ismail et al., 2017), where a higher number of new cases were recorded. Lesser AQI values $(<50)$ were recorded at the end of the MCO period, and there was a decrease in the new cases. During the CMCO period, most of the values were $>50 \mathrm{AQI}$, with a record of few spikes in new cases. In the RMCO period, the AQI values were higher $(>50)$, compared with other lockdown periods. This clearly indicates that the partial release of lockdown in Kuala Lumpur has increased the industrial activities, which affected the air quality, thereby influencing the pandemic spread.

\section{Selangor}

There was an increase in AQI values $(>50)$ prior to implementation of MCO, during the pre lockdown period, showing a higher record of new cases (Figure 4). During the MCO period, there was a declining trend of AQI values observed, and it has a good correlation with the decreasing number of new cases. In the CMCO period, there was a sharp increase in AQI values, which was correlated with the high number of cases. During the RMCO period, there was a gradually increasing trend of AQI values, predominantly $>50$ and fewer new cases were recorded. Overall, it is interesting to observe that, there was a declining trend of AQI values from pre lockdown to MCO periods, and started increasing from CMCO to RMCO period. This indicates that the effective controls during $\mathrm{MCO}$ periods have reduced the industrial activities in the city, which has improved the air quality. Subsequently, the air quality got deteriorated due to the partial release of industrial activities during $\mathrm{CMCO}$ and $\mathrm{RMCO}$ periods.

\section{Putrajaya}

During pre-lockdown period, mostly high AQI (>50) values were recorded, with a greater number of cases at the end of the period (Figure 5). In the MCO period, higher AQI values were recorded at the initial phase, with a greater number of cases. There was a sudden drop in AQI values at the end of this period with a decrease in the number of cases. The AQI values started increasing again during the $\mathrm{CMCO}$ period, with few spikes of new cases. In the RMCO period, the AQI values continued to increase and crossed above $50 \mathrm{AQI}$, which clearly shows moderate air quality even though fewer number of new cases were recorded.

\section{Sabah}

In comparison with central Peninsular Malaysia, Sabah has lesser industrial activities and a human population. It was observed that the AQI values are well below 50 from MCO to RMCO periods (Figure 6). There was a 


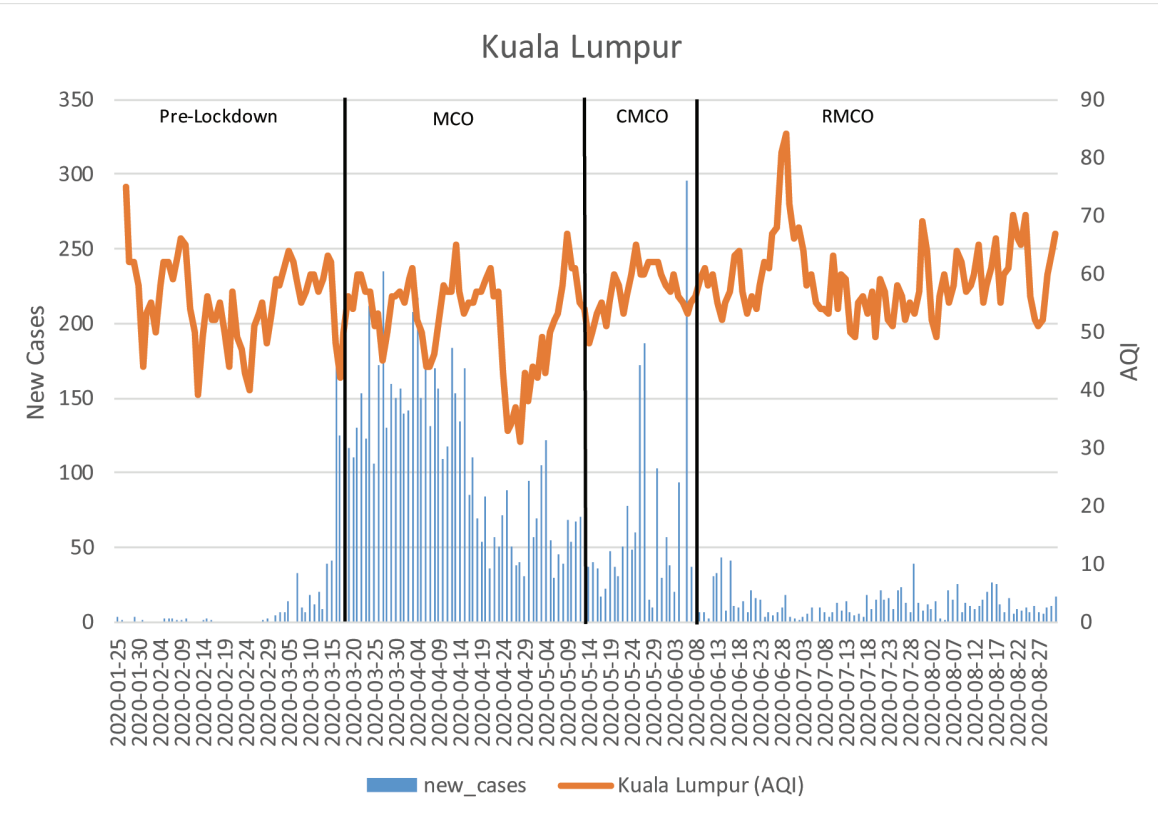

Figure 3: Variation of air quality with respect to the new cases in Kuala Lumpur during the study period.

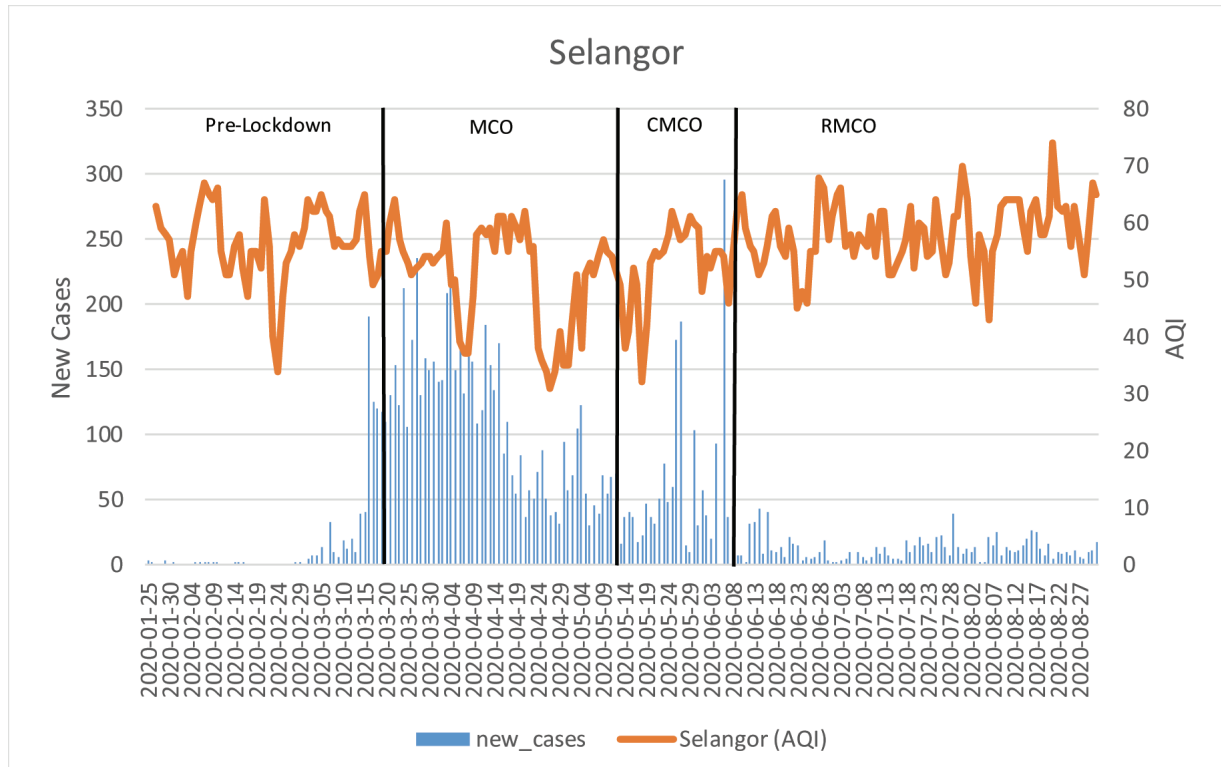

Figure 4: Variation of air quality with respect to infected cases in Selangor during the study period.

declining trend of AQI values $(<50)$ in the $\mathrm{MCO}$ and $\mathrm{CMCO}$ periods. This trend is well correlated with the decrease in the number of new cases in the city. There was a slight increase in AQI values, but well below 50 , with reducing the number of new cases during the RMCO period.

The average AQI values indicate that the air quality was improved during the lockdown period (MCO) irrespective of locations (Figure 7), where most of the industries were closed and movement of vehicles was controlled. But, the quality of air declined during post lockdown (RMCO) particularly in central Peninsular Malaysia due to the movement relaxation. In Sabah, the air quality was well within the quality throughout the study period, particularly in post-lockdown period.

\section{Effect of Precipitation to the Air Quality}

Rainfall is recognised by the removal of atmospheric pollutants, especially particulate matter, which carry viruses in the air, as one of the key natural processes 


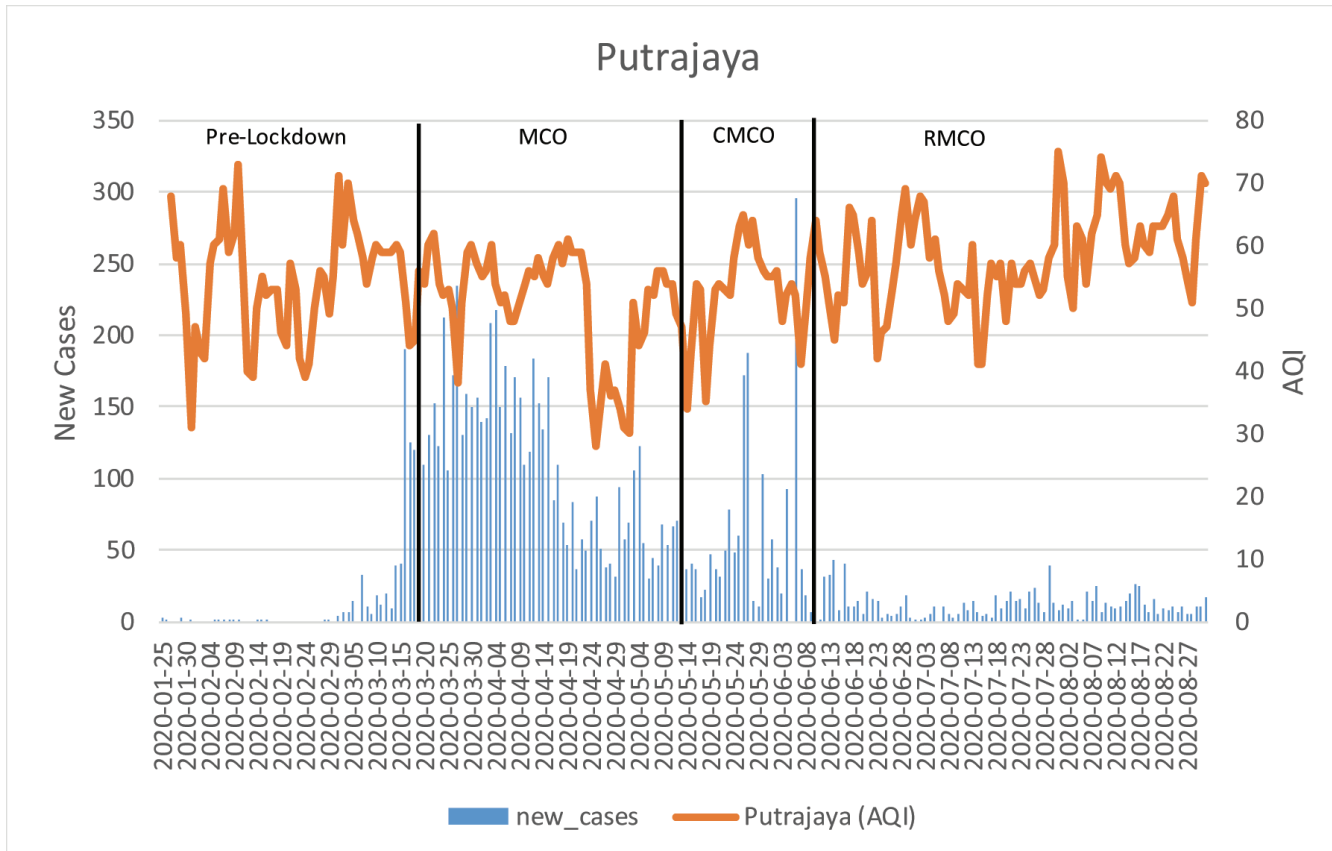

Figure 5: Variation of air quality with respect to infected cases in Putrajaya during the study period.

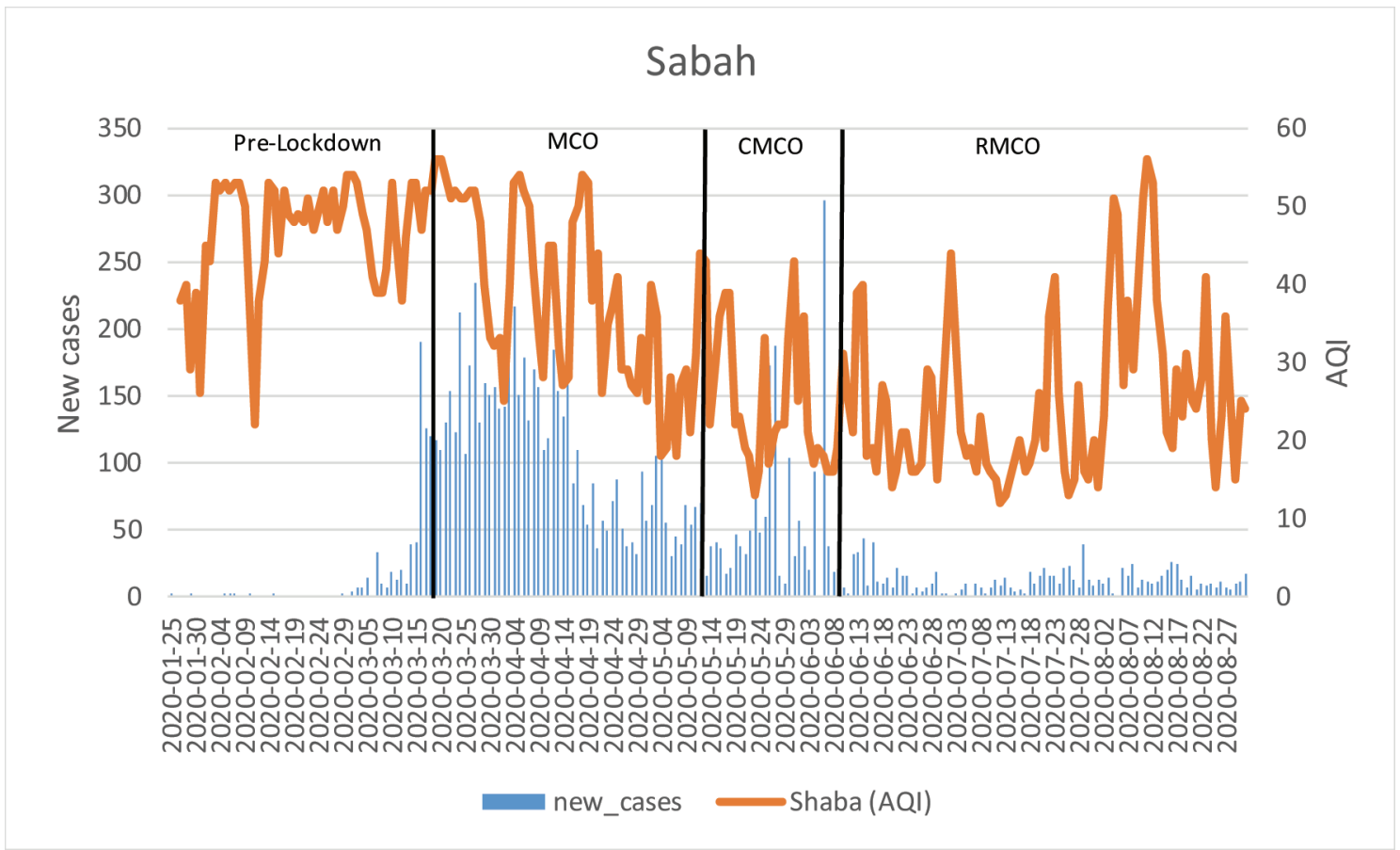

Figure 6: Variation of air quality with respect to infected cases in Sabah during the study period.

for improving air quality (Guo et al., 2014). So, an attempt was made to correlate the precipitation rates with air quality at different lockdown periods in Kuala Lumpur (representing central Peninsular Malaysia) and Sabah (representing East Malaysia).

In Kuala Lumpur, there was a significant variation in the precipitation rates across the study period. It was observed that during the initial and the final stages of the MCO period, the average precipitation rate was $<10 \mathrm{~mm}$ and AQI was $>50$, where the new cases were highly recorded (Figure 8). Alternatively, in the midMCO period which represents the inter-monsoon, there was a sharp increase of precipitation $(>10 \mathrm{~mm})$ and $\mathrm{AQI}<50$ with the less number of new cases. During 


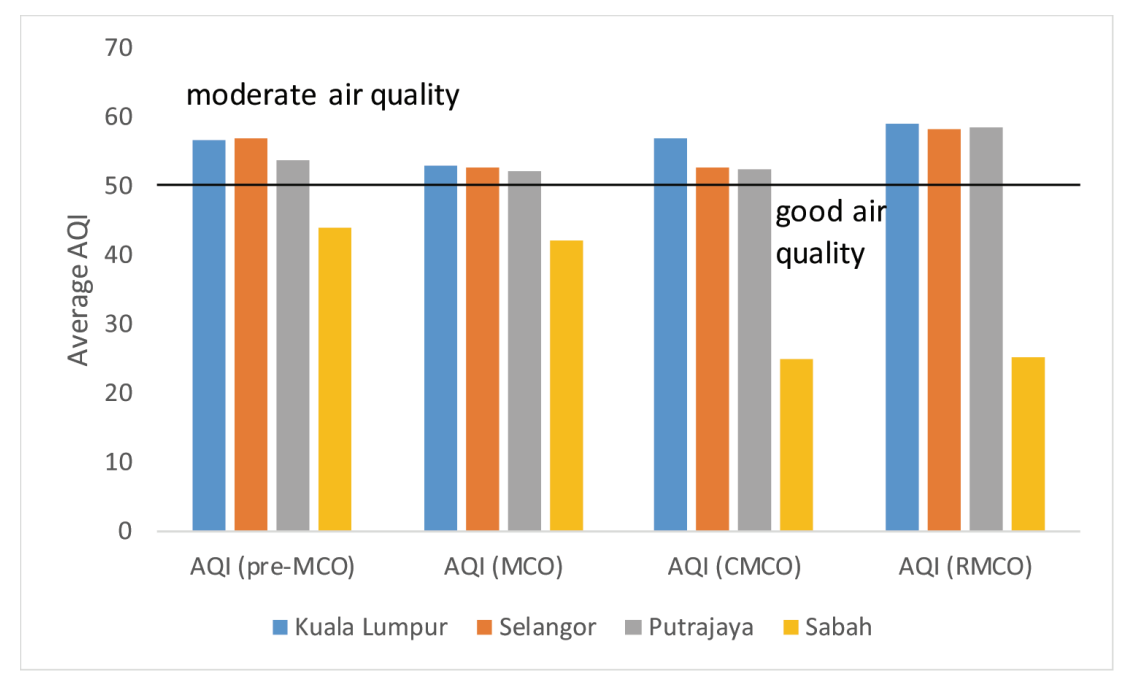

Figure 7: Trend of average AQI values during the study period.

the CMCO period representing SW monsoon, the lesser amount of precipitation (average $<10 \mathrm{~mm}$ ) with high AQI values ( $>50)$ was recorded with reports of few new cases. It is clearly observed that an inverse relationship between the amount of precipitation and AQI (i.e. less precipitation and high AQI values and vice versa) affects the pandemic spreading during RMCO (SW monsoon).

In Sabah, the amount of precipitation was quite constant $(<10 \mathrm{~mm})$ from pre lockdown to mid-MCO periods representing NE monsoon (Figure 9). The subsequent increase in precipitation was observed, particularly in late MCO (inter-monsoon) and CMCO and RMCO periods (SW monsoon). An inverse relationship was observed between precipitation rate and AQI in the MCO period, which also supports the fluctuation of new cases. It is obvious that in the CMCO and RMCO periods, substantial precipitation $(>10$ $\mathrm{mm}$ ) combined with low AQI values (50) considerably restricted pandemic transmission. Overall, the above inferences suggest that the infected droplet nuclei in the air can be washed out by high rainfall and the transmission of the virus has thus decreased (Comrie 2007; Lowen et al., 2007).

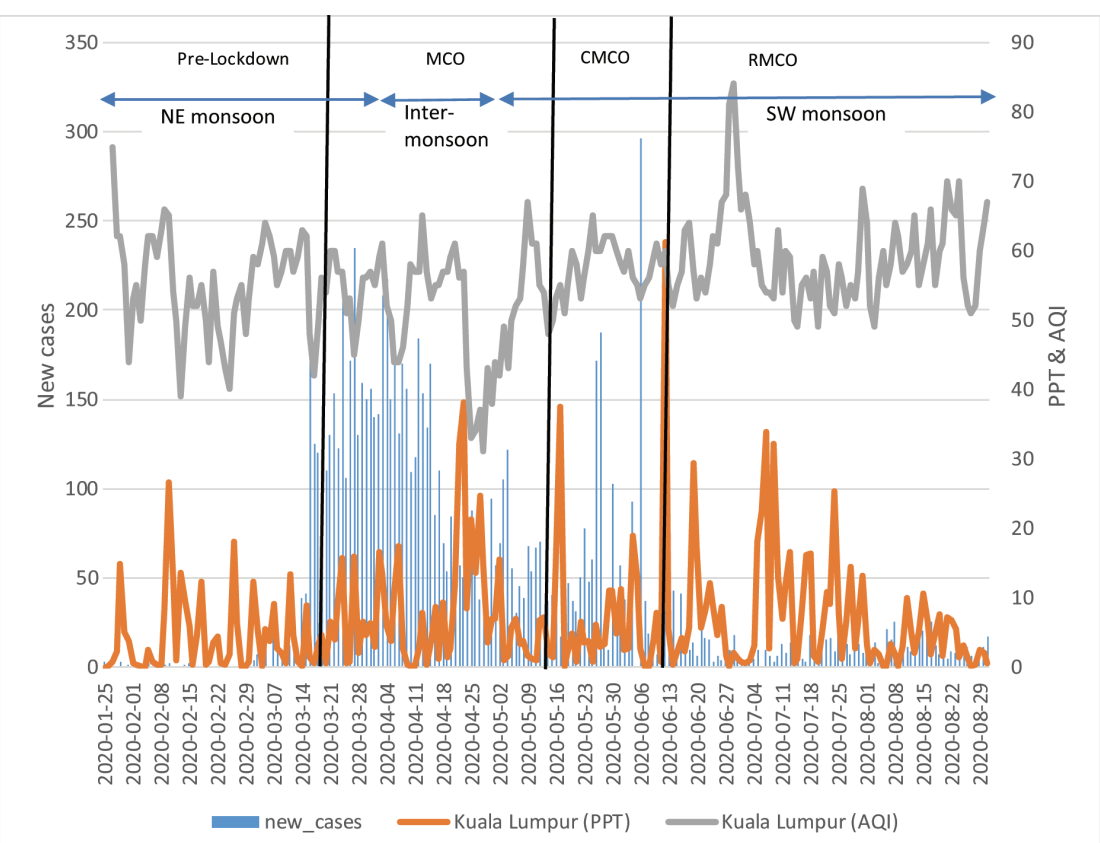

Figure 8: Correlation between precipitation and AQI to depict the washout effect of air pollutants in Kuala Lumpur. 


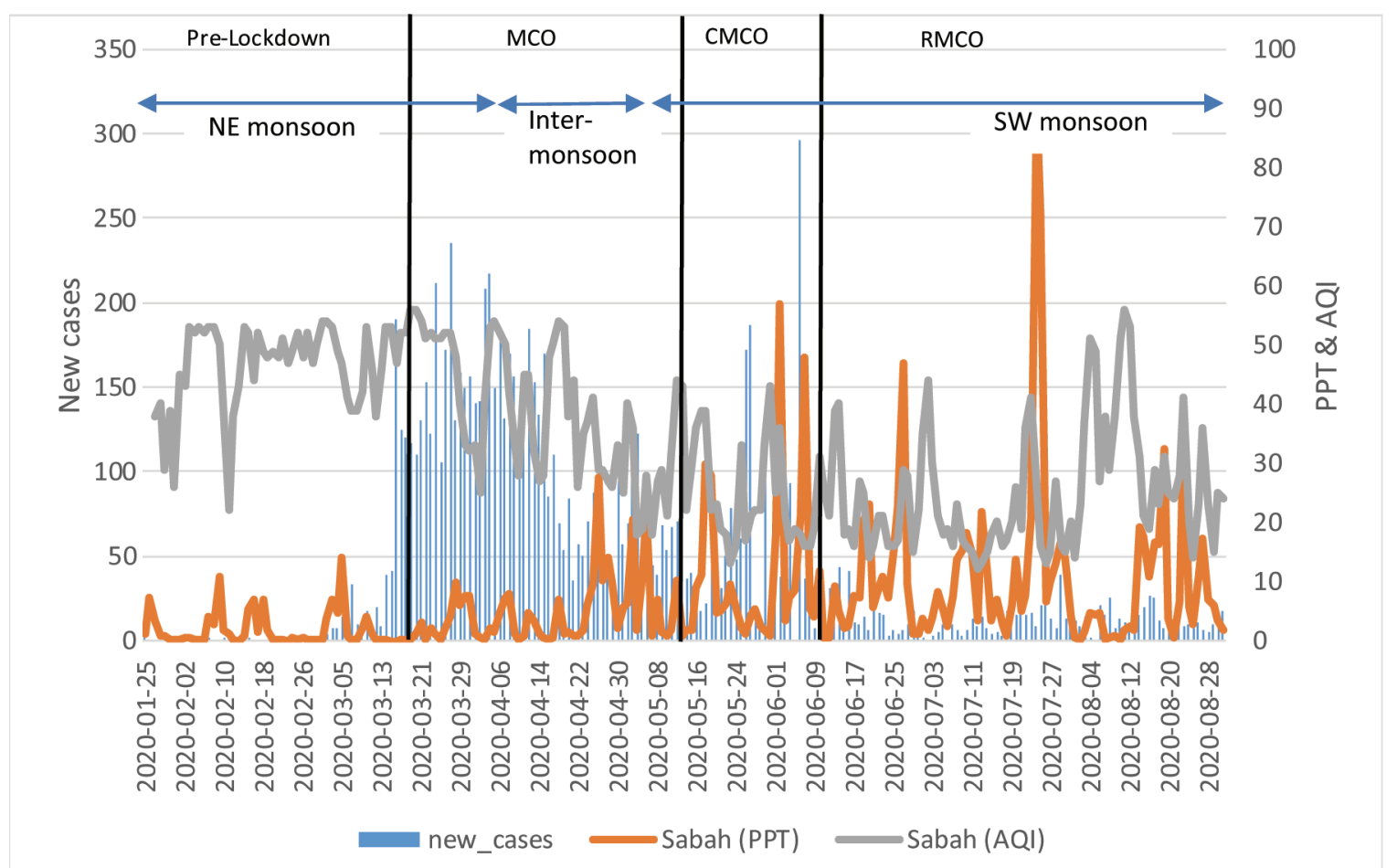

Figure 9: Correlation between precipitation and AQI to depict the washout effect of air pollutants in Sabah.

\section{Air Movement}

In order to identify the variation in source contribution of air particles reaching the study area, backward air mass trajectory corresponding to four different time periods (pre-lockdown, MCO, CMCO and RMCO) representing three monsoons (NE monsoon, intermonsoon and SW monsoon) was generated using an HYSPLIT transport model. Geographically, Kuala Lumpur, Selangor and Putrajaya cities are located close to each other. So, Kuala Lumpur was chosen to represent central Peninsular Malaysia, and Sabha represented East Malaysia.

In air quality and pollutant movement modelling, the backward trajectory analysis is the best available method that helps to provide detailed input on the origin and sources of contaminants in the atmosphere (Tatsuta et al., 2017; Tu et al., 2019). Winds, which carry particulate matter from different adjoining locations can also cause the degradation of air quality in a specific region (Steyn and Castelli, 2010). The HYSPLIT analysis was attempted by considering different months; first week of March 2020, (representing pre-lockdown and NE monsoon); third week of April 2020 (after the implementation of MCO and inter-monsoon); fourth week of May 2020 (after the initiation of CMCO and SW monsoon) and finally the fifth week of July 2020 (after the implementation of RMCO and SW monsoon) were selected and modeled at three different heights, i.e., 100, 500 and $1000 \mathrm{~m}$ above ground level.

It was observed that air pollutants enter central Peninsular Malaysia from the northeast direction during the pre-lockdown period (NE monsoon) and display a mixed contribution, i.e. from the ocean (the South China Sea) and the land area with predominant ocean contribution (Figure 10). The same trend and source were identified in the MCO period (inter-monsoon). A contrasting characteristic was observed during the CMCO period (SW monsoon), which shows the dominance of the west direction with less contribution from land and major contribution from the southern Indian Ocean. In the RMCO period (SW monsoon), central Peninsular Malaysia received dominant pollutants from the south direction with a major contribution from the land area of Indonesia.

In east Malaysia (Sabha), the air pollutants travelled from the northeast direction with mixed contribution from the ocean (Pacific Ocean, South China sea) and landmass of Philippines during pre lockdown period (NE monsoon) (Figure 11). In the MCO period (intermonsoon), dominant pollutants were derived from the east direction and show the major contribution from the Pacific Ocean, with minor influence from land area. But during CMCO (SW monsoon), the air pollutants dominantly travelled from the south direction, with the 
NOAA HYSPLIT MODEL

(a) Backward trajectories ending at 1000 UTC 06 Mar 20 GDAS Meteorological Data

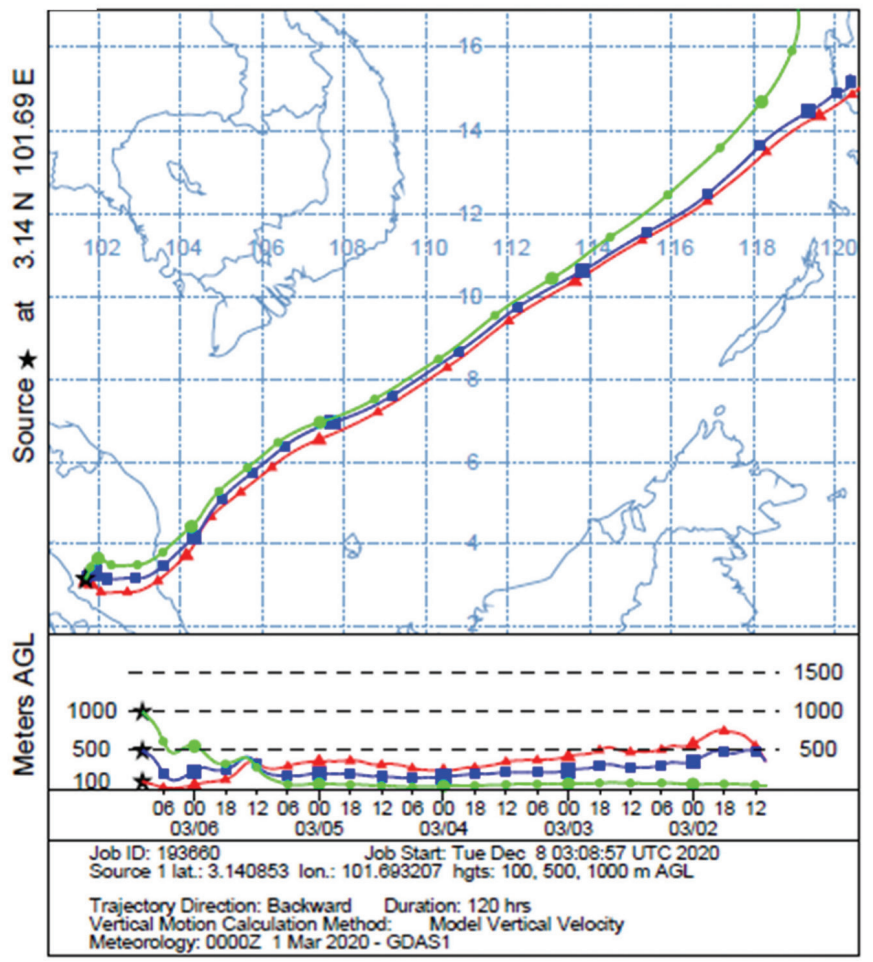

NOAA HYSPLIT MODEL

(c)

Backward trajectories ending at 1000 UTC 23 May 20 GDAS Meteorological Data

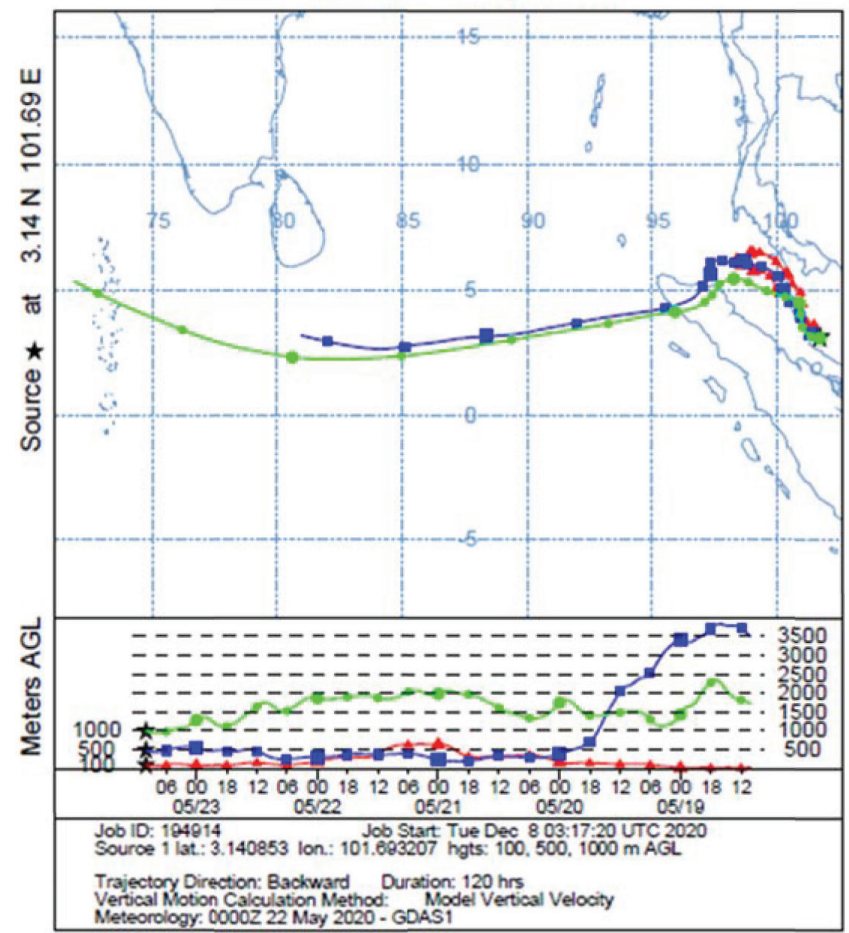

NOAA HYSPLIT MODEL

(b) Backward trajectories ending at 1000 UTC 16 Apr 20 GDAS Meteorological Data

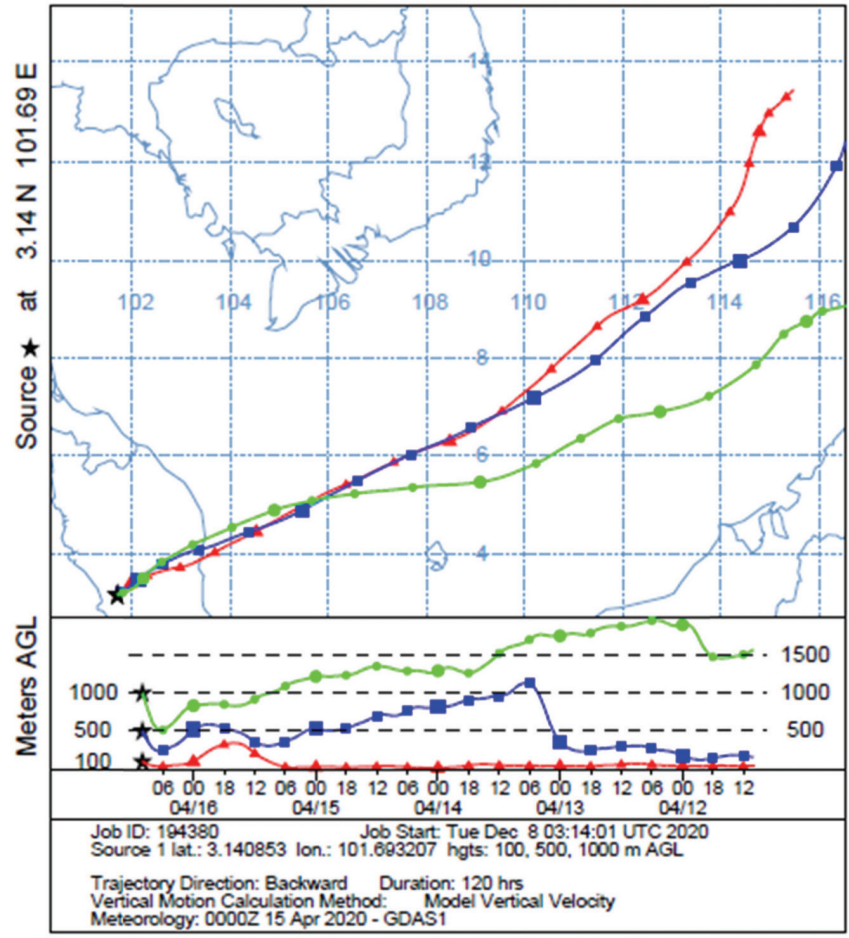

NOAA HYSPLIT MODEL

(d)

Backward trajectories ending at 1000 UTC 29 Jul 20 GDAS Meteorological Data

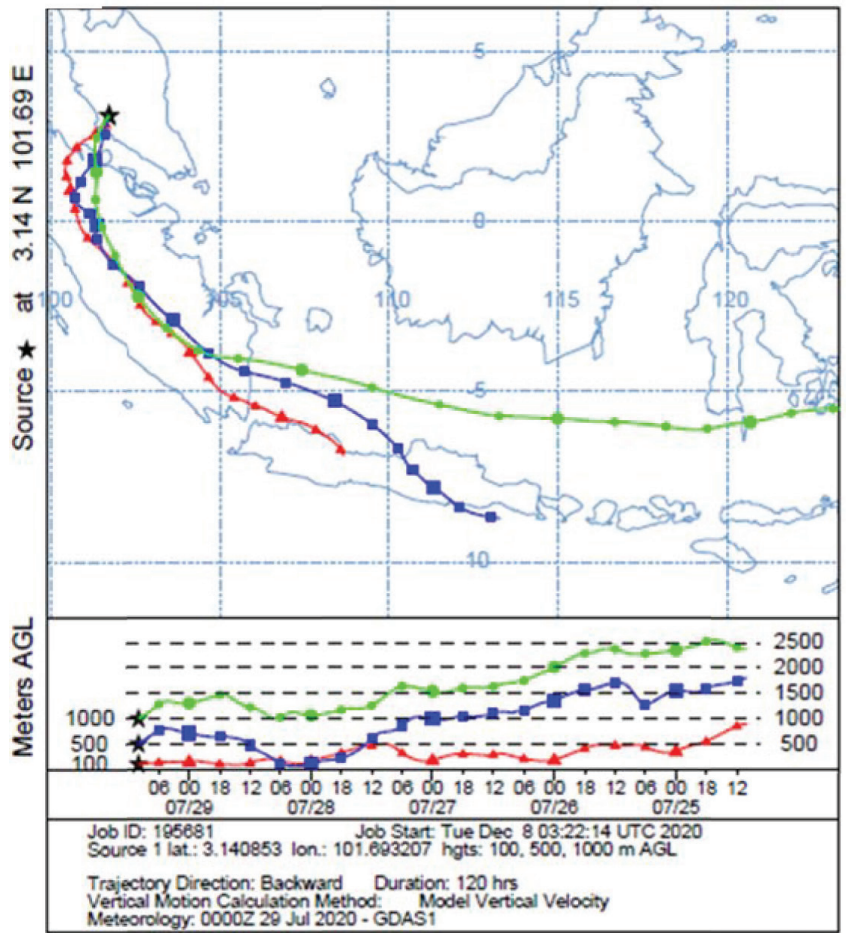

Figure 10: Air mass backward trajectories reaching Peninsular Malaysia during (a) pre lock down (b) MCO (c) CMCO (d) RMCO. 
NOAA HYSPLIT MODEL

(a)

Backward trajectories ending at 1000 UTC 05 Mar 20 GDAS Meteorological Data

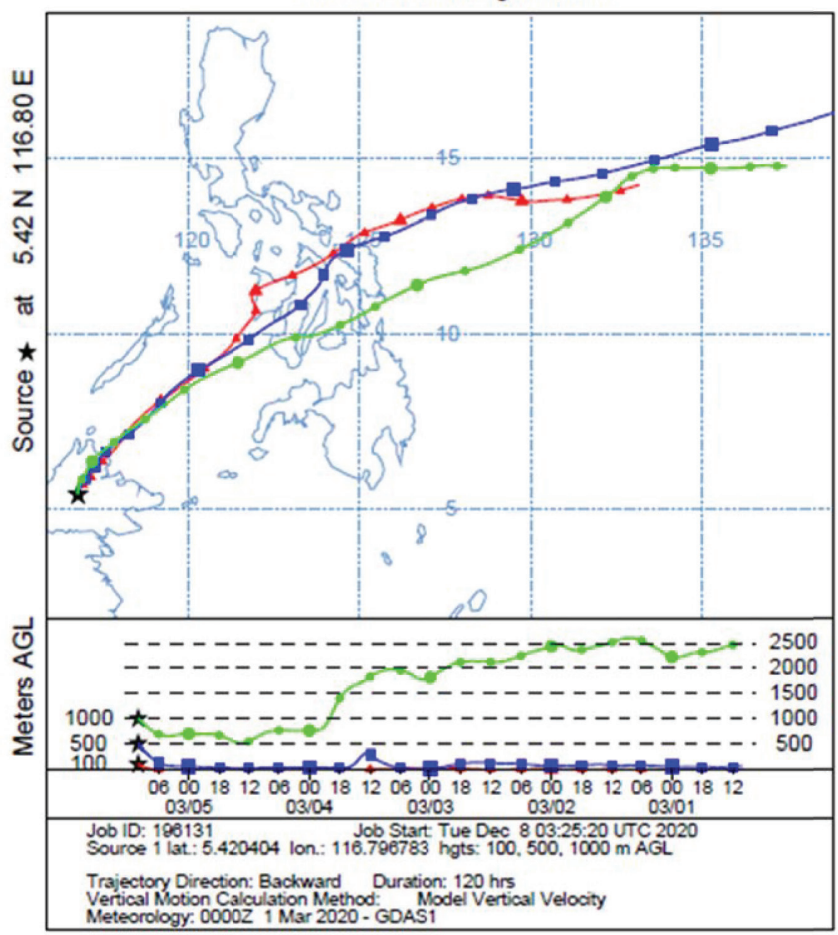

NOAA HYSPLIT MODEL

(c) Backward trajectories ending at 1000 UTC 25 May 20 GDAS Meteorological Data

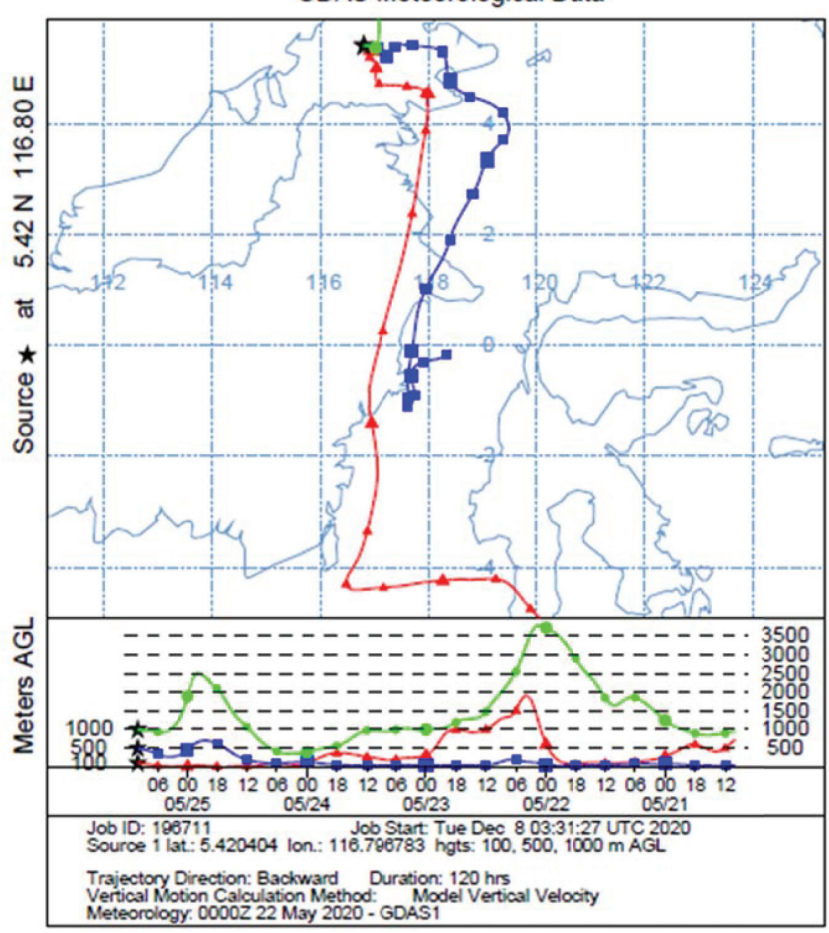

NOAA HYSPLIT MODEL

(b) Backward trajectories ending at 1000 UTC 16 Apr 20 GDAS Meteorological Data

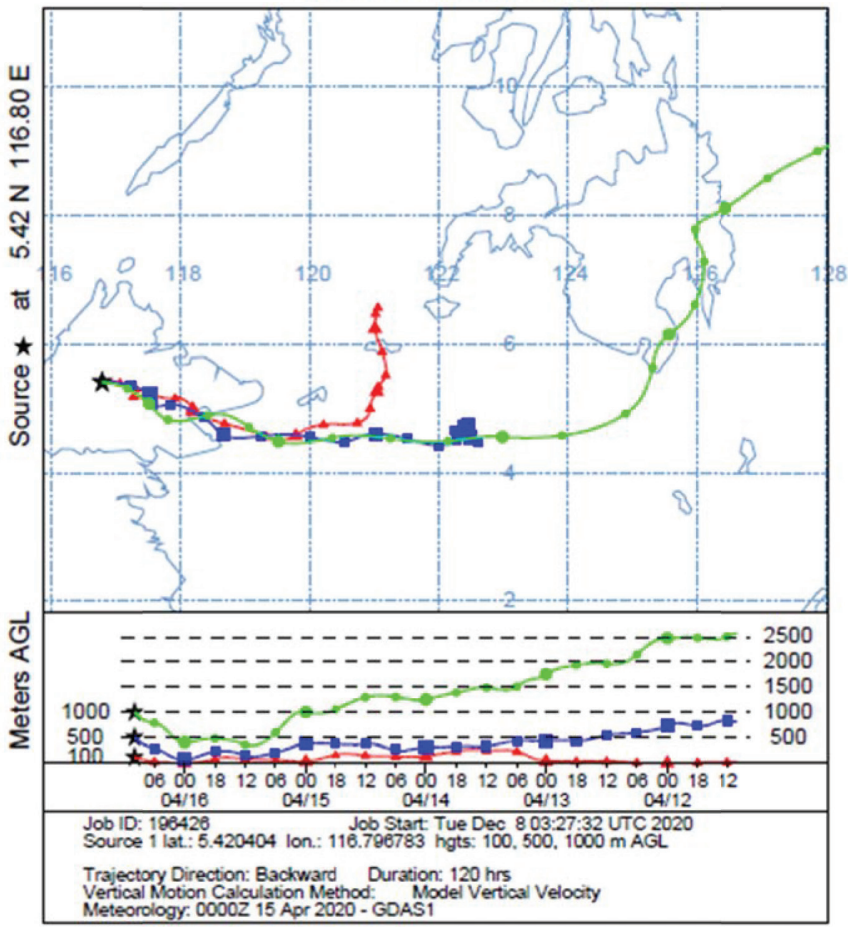

NOAA HYSPLIT MODEL

(d) Backward trajectories ending at 1000 UTC 29 Jul 20 GDAS Meteorological Data

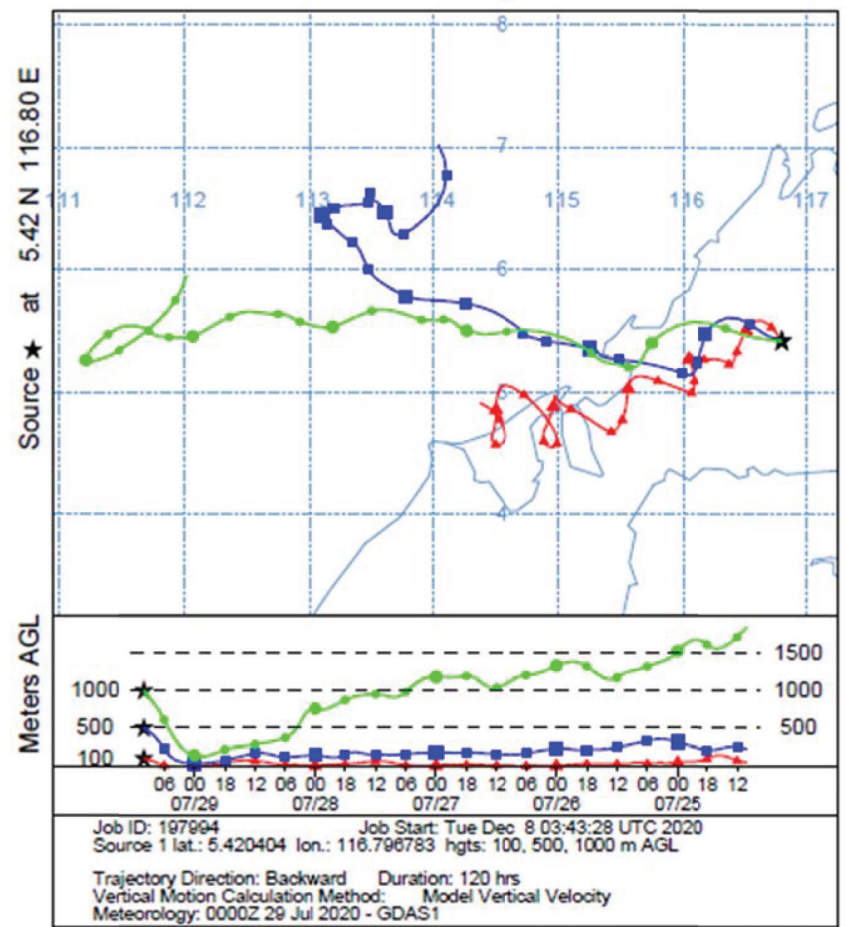

Fig 11. Air mass backward trajectories reaching Sabah during (a) pre lock down (b) MCO (c) CMCO (d) RMCO. 
majority contribution from the land area. A different scenario was observed during RMCO (SW monsoon), where the air pollutants from the west direction with a major contribution from the South China Sea. It is interesting to note that the pollutants are also contributed from the land area with $500 \mathrm{~m}$ elevation.

In general, the change in direction of air mass trajectories during CMCO and RMCO was observed. This change in direction might have also lead to the variation in the atmospheric air quality leading to the changes in the number of new cases.

\section{Conclusions}

The study has identified the influence of air quality on the COVID-19 pandemic spreading in Malaysia. It was observed that an increase of new cases was recorded in the early lockdown (MCO) period, and gradually reduced in the post-lockdown period (CMCO and RMCO), which indicates the effectiveness of standard operation plans to ease the pandemic spread. In general, moderate air quality was observed in central Peninsular Malaysia, whereas good air quality in Sabah. High precipitation was recorded during SW monsoon, followed by inter-monsoon and NE monsoon. The air quality was improved in central Peninsular Malaysia, during the lockdown period, which is mainly due to the shutdown of industrial activities and reduction in vehicle emissions coupled with the monsoonal rainfall. High precipitation in Sabah has improved the air quality through the washout effect, particularly during the post-lockdown period of SW monsoon. The air mass movement modelling indicates a mixed contribution predominantly from the ocean in both central Peninsular Malaysia and Sabah during the lockdown period. The post-lockdown period indicates the source of pollutants was mostly from the land area, particularly in the lower atmosphere (100 m elevation above ground level), which clearly indicates that the local industrial and vehicle emission affects the air quality. Overall, this study concluded that air quality is also a controlling factor for the transmissivity of viruses besides social distancing and individual immunity.

\section{Acknowledgements}

The authors thank K. Shankar for preparing the study location map.

\section{References}

Abdullah, J.M., Wan Ismail, W.F.N., Mohamad, I., Ab Razak A., Harun, A., Musa, K.I. and Lee, Y.Y., 2020. A critical appraisal of COVID-19 in Malaysia and beyond. Malays J Med Sci, 27(2): 1-9. https://doi. org/10.21315/ mjms2020.27.2.1.

Afroz, R., Hassan, M.N. and Ibrahim, N.A., 2003. Review of air pollution and health impacts in Malaysia. Environ Res. 92(2): 71-77.

Aghamohammadi, N. and Isahak, M., 2018. Climate change and air pollution in Malaysia. In: Climate change and air pollution. Springer, Berlin, pp 241-254.

Azlan., Arina, Anis., Hamzah, Mohammad Rezal., Jen Tham, Id Sern. and Hadi, Suffian Id Ayub, 2020. Public knowledge, attitudes and practices towards COVID-19: A cross-sectional study in. Plos One. 10.1371/journal. pone. 0233668 .

Brohi, S., Pillai, T., Asirvatham, D., Ludlow, D. and Bushell, J., 2018. Towards smart cities development: A study of the public transport system and traffic-related air pollutions in Malaysia. In: IOP Conference Series: Earth and environmental science. IOP Publishing, 167: 012015.

Chauhan, A. and Singh, R.P., 2020. Decline $\mathrm{PM}_{2.5}$ concentrations over major cities around the world associated with COVID-10. Environmental Research, 109634.

Che Mat, N.F., Edinur, H.A., Abdul Razab, M.K.A. and Safuan, S., 2020. A single mass gathering resulted in massive transmission of COVID-19 infections in Malaysia with further international spread. Journal of Travel Medicine. 1-4.

Chen, B., Liang, H., Yuan, X., Hu, Y., Xu, M., Zhao, Y., Zhang, B., Tian, F. and Zhu, X., 2020. Roles of meteorological conditions in COVID-19 transmission on a worldwide scale. doi:10.1101/2020.03.16.20037168.

Chng, L.K., Abdullah, A.M., Sulaiman, W.N.A. and Ramli, M.F., 2010. The effects of improved land use on the meteorological modeling in Klang Valley region Malaysia. Environ. Asia. 3: 117-123.

Comrie, A., 2007. Climate change and human health. Geography Compass 2007; 1(3): 325-339.

Department of Environment Malaysia (DOE). 1997. A Guide to Air Pollution Index in Malaysia (API). Ministry of Science, Technology and Environment, Kuala Lumpur.

Department of Environment Malaysia (DOE). 2012. Malaysia Environmental Quality Report, Ministry of Science, Technology and Environment, Kuala Lumpur.

Dominick, D., Juahir, H., Latif, M.T., Zain, S.M. and Aris, A.Z., 2012. Spatial assessment of air quality patterns in Malaysia using multivariate analysis. Atmospheric Environment, 60: 172-181. 
DOS, 2012. Annual report 2012. Department of Statistics DOS, Malaysia.

Enger, E.D. and Smith, B.F., 2000. Environmental science: A study of interrelationships (7th ed.). Boston, Mass: McGraw-Hill.

Guo, L.C., Bao, L.-J., She, J.-W. and Zeng, E.Y., 2014. Significance of wet deposition to removal of atmospheric particulate matter and polycyclic aromatic hydrocarbons: A case study in Guangzhou, China. Atmos. Environ., 83: 136-144.

Isiyaka, H.A. and Azid, A. 2015. Air quality pattern assessment in Malaysia using multivariate techniques. Malaysian Journal of Analytical Sciences, 19(5): 966-978.

Ismail, A.Z., Abdullah, A.M. and Samah, M.A.A., 2017. Environmetric study on air quality pattern for assessment in Northern region of Peninsular Malaysia. J. Environ. Sci. Technol., 10: 186-196.

Lambert, A.L., Mangum, J.B., DeLorme, M.P. and Everitt, J.I., 2003. Ultrafine carbon black particles enhance respiratory syncitial virus-induced airway reactivity, pulmonary inflammation, and chemokine expression. Toxicol Sci., 73: 339-348.

Ling, O.H.L., Ting, K.H., Shaharuddin, A., Kadaruddin, A. and Yaakob, M.J. 2010. Urban growth and air quality in Kuala Lumpur city, Malaysia. Environ. Asia., 3: 123-128.

Lowen, A.C., Mubareka, S., Steel, J. and Palese, P., 2007. Influenza virus transmission is dependent on relative humidity and temperature. PLOS Pathog. 3(10): 14701476. https://doi.org/10.1371/journal.ppat.0030151.

Ma, Y., Zhao, Y., Liu, J., He, X., Wang, B., Fu, S. and Luo, B., 2020. Effects of temperature variation and humidity on the death of COVID-19 in Wuhan, China. Sci. Total Environ., 138226 https://doi.org/10.1016/j.scitotenv.2020.138226.

Mabahwi, N.S., Leh O.L.H. and Omar, D., 2015. Urban Air Quality and Human Health Effects in Selangor, Malaysia. Procedia - Social and Behavioral Sciences, 170(27): 282-291.

Muhammad, S., Long, X. and Salman, M., 2020. COVID-19 pandemic and environmental pollution: A blessing in disguise? Sci Total Environ, 138820

Otmani, Anas., Benchrif, Abdelfettah., Tahri, Mounia., Bounakhla, Moussa., Chakir El, Mahjub., El Bouch, Mohammed and Krombi, M'hamed., 2020. Impact of Covid-19 lockdown on PM10, $\mathrm{SO}_{2}$ and $\mathrm{NO}_{2}$ concentrations in Salé City Morocco. Science of the Total Environment. 735: 139541, https://doi.org/10.1016/j. scitotenv.2020.139541

Poole, L., 2020. Seasonal influences on the spread of SARS-CoV-2 (COVID19), causality, and forecastabililty (3-15-2020). SSRN Electronic Journal. doi:10.2139/ ssrn.3554746.

Ramanathan, V. and Feng, Y., 2009. Air pollution, greenhouse gases and climate change: Global and regional perspectives. Atmospheric Environment, 43(1): 37-50.

Sajadi, M.M., Habibzadeh, P., Vintzileos, A., Shokouhi, S., Miralles-Wilhelm, F. and Amoroso, A., 2020. Temperature and latitude analysis to predict potential spread and seasonality for COVID-19 (Available at SSRN 3550308).

See, K.C., Liew, S.M., et al., 2020. COVID-19: Four paediatric cases in Malaysia. Int J Infect Dis., 94: 125-127. doi: 10.1016/j.ijid.2020.03.049.

Steyn, D.G. and Castelli, S.T., 2010. Air pollution modeling and its application. Springer, New York. pp 4-5.

Tatsuta, S., Shimada, K., Chan, C.K., Kim, Y.P., Lin, N.H., Takami, A. and Hatakeyama, S., 2017. Contributions of long-range transported and locally emitted nitrate in sizesegregated aerosols in Japan at Kyushu and Okinawa. Aerosol Air Qual Res, 17: 3119-3127.

Tu, X., Lu, Y., Yao, R. and Zhu, J., 2019. Air quality in Ningbo and transport trajectory characteristics of primary pollutants in autumn and winter. Atmosphere, 10: 120. https://doi.org/10.3390/atmos10030120

Wang, Y., Wang, Y., Chen, Y. and Qin, Q., 2020. Unique epidemiological and clinical features of the emerging 2019 novel coronavirus pneumonia (COVID-19) implicate special control measures. J. Med. Virol., 92: 568-576.

Wang, P., Chen, K., Zhu, S., Wang, P. and Zhang, H., 2020a. Severe air pollution events not avoided by reduced anthropogenic activities during COVID-19 outbreak. Resour Conserv Recycl, 158: 104814

Wu, F., Zhao, S., Yu, B., Chen, Y.-M., Wang, W., Song, Z.G., Hu, Y., Tao, Z.W., Tian, J.H., Pei, Y.Y., Yuan, M.L., Zhang, Y.L., Dai, F.H., Liu, Y., Wang, Q.M., Zheng, J.J., Xu, L., Holmes, E.C. and Zhang, Y.Z., 2020. A new coronavirus associated with human respiratory disease in China. Nature, 579: 265-269. doi:10.1038/s41586-020-2008-3. 